\title{
People Centered Innovation: Enabling Lean Integrated Project Delivery and Disrupting the Construction Industry for a More Sustainable Future
}

\author{
William Paolillo, ${ }^{1,2}$ Branka V. Olson, ${ }^{1,3}$ and Edward Straub ${ }^{1,4}$ \\ ${ }^{1}$ Case Western Reserve University, Cleveland, OH, USA \\ ${ }^{2}$ Welty Building Company, Fairlawn, OH, USA \\ ${ }^{3}$ Sindik Olson Associates Architecture, Los Angeles, CA, USA \\ ${ }^{4}$ Velouria Systems LLC, Brighton, MI, USA \\ Correspondence should be addressed to William Paolillo; wjpaolillo@gmail.com
}

Received 18 February 2016; Accepted 17 April 2016

Academic Editor: Eric Lui

Copyright (C) 2016 William Paolillo et al. This is an open access article distributed under the Creative Commons Attribution License, which permits unrestricted use, distribution, and reproduction in any medium, provided the original work is properly cited.

People-centered innovation is a paradigm shift in the construction industry. It is derived from the supposition that people not methods, schedules, or budgets deliver projects. Our data suggest that a multilevel, multidisciplinary project team through shared vision, values, and a common vernacular defines, designs, and delivers more successful projects than traditional methods. These projects meet the needs of shareholders, the community, stakeholders, and the planet. We employ the concepts of emotional intelligence and agency theory to explain an integrated project delivery (IPD) construction project using lean tactics that not only delivered, but also exceeded expectations resulting in a six-month schedule acceleration and $\$ 60 \mathrm{M}$ savings over the original estimated cost of the project calculated assuming traditional project delivery methods. The safety rating for this project was $50 \%$ better than the national average and the expected improvement in operating margin for the new building is $33 \%$ greater. This paper introduces the notion of people-centered innovation to an industry that has struggled to adapt and show positive results over recent decades. Our case study describes the significance of people-centered innovation in construction project delivery. We discuss the implications for the construction industry going forward.

\section{Introduction}

By 2040, commercial buildings will cover more than 109 Billion square feet of floor space. That is a $32 \%$ increase from 2012. Commercial space includes everything from office buildings to warehouses and includes schools, hospitals, and churches. The long term impacts of commercial projects are becoming increasingly more detrimental to human life on the planet.

From an environmental perspective, the process of building commercial structures negatively impacts the planet's natural resource: energy (18.3 quadrillion Btu of primary energy in 2010), water (10.2 billion gallons per day in 2005), and materials (primarily lumber and cement). From a life cycle perspective, commercial buildings add to the impact on the environment in three areas: waste (103 million tons of construction and demolition waste were produced in 2003 alone.), indoor air contaminants (The concentration of Volatile Organic Compounds (VOC's) in indoor air is 2 to 3 times greater than in the natural environment.), and greenhouse gas emissions (18\% of all US carbon dioxide emissions in 2012 were emitted from commercial buildings.) [1]. Decisions made today impact generations to come when one considers that a building's life cycle is expected to last from 50 to 100 years.

The long term considerations are generally not a priority concern in the construction industry collective mindset. Adding to the complexity of project delivery are clients who want to hear two things when the project is finished: that it was finished on time and that it was finished on budget. 
Over the last fifty years the construction industry has seen productivity decrease by $10 \%$ with more than $50 \%$ of projects either over budget or behind schedule. Over the same time business productivity (non-farm and mining) has increased over $250 \%$. Additionally, $60 \%$ of the activity on a construction project can be classified as waste (McGraw Hill Smart Market report) and the construction industry is one of the few places where customers and suppliers frequently sue each other. One of our interviewees commented, "I hate to admit it but it is true, [the commercial construction industry] is somewhat confrontational. It's cracking the whip and toeing the line, and 'you are going to get this done by this date."

From a design perspective, project delivery consists of two major phases, problem definition and problem solution. Problem definition emphasizes project requirements and constraints, especially with regard to functional outcomes, physical space, and, of course, cost, and provides the reference framework within which a solution can be defined [2]. Problem solution is the act and process of delivering something that meets all of the project requirements. Current project delivery structures limit the participation of critical team members by devoting only about $10 \%$ of activity to the problem definition and $90 \%$ to the solution space [3]. The creativity, passion, and expertise of the entire project team go unrealized as individuals and management are mired in transactional relationships exchanging fees for services. The design-bid-build contractual process has caused a focus on the present, the initial construction cost. There is no reward for collaborating outside one's specific project activity.

This study explores the procedural and social elements of a large commercial construction project utilizing people centered innovation (PCI) to maximize the effect of integrated project delivery (IPD). People centered innovation is the development of a culture that includes collaboration, coinnovation, and cocreation [4]. In the context of project delivery, people centered innovation is defined by participating stakeholders at all levels and disciplines having active access and influence into the project definition and delivery process. PCI is characterized by the relational climate where the participants cocreate and form a coherent team based on a shared vision, values, and vernacular. We found that process does not drive innovation and/or the capacity to create an exceptional building, people do.

We examined an IPD implementation that resulted in $\$ 60 \mathrm{M}$ savings (The original estimated cost of the project was $\$ 240 \mathrm{M}$ assuming traditional project delivery methods. The final cost was $\$ 178 \mathrm{M}$.) and a six-month reduction in the schedule. The safety rating for this project was $50 \%$ better than the national average and the expected improvement in operating margin for the business occupying the new building is $33 \%$ greater than the estimate associated with the original plans.

\section{Theory}

Our analysis leveraged a number of theories and concepts. It is important to understand what integrated project delivery (IPD) is in order to help distinguish it from traditional project delivery. Integrated project delivery is a relational contract between the owner, contractor, and architect to construct a building (McGraw Hill Smart Market Report). The premise is that the three entities become stakeholders in the outcome. As the project progresses from initial design through completion, the team leverages early, concurrent efforts of the core team and associated subconsultants. With input and agreement from all three stakeholder groups and subconsultants, a fully coordinated solution and project plan is devised that meets program requirements within the available schedule and budget. A major departure from traditional project delivery methods is that all issues must be resolved by the project stakeholder team and no issues are left unresolved [5]. Interdependency in an IPD project is represented by the degree of reciprocal interaction between the disciplines. Projects are integrated through coordination, communication, and interaction [6]. A project team structure in integrated project delivery requires the skill of leading and following and pulling and pushing. Integrated project delivery is more than a methodology and not all IPD projects are equally successful. The reason for this is that contracts and processes do not deliver projects, people do. The quality of human interactions and individual and team motivation control the execution of the strategies and tactics, particularly self-organization.

Emotional intelligence is "the capacity for recognizing our own feelings and those of others, for motivating ourselves, and for managing emotions well in ourselves and in our relationships" [7, page 317]. It is a prerequisite for creating common shared vision, values, and vernacular across the many teams of contractors, subcontractors, users, designers, and suppliers all participating in project delivery. Emotional intelligence, specifically empathy and self-awareness, is what effective leaders use to create connection between team members [8]; engender better relationships; improve ability to deal with conflict; encourage open communication; and drive better project outcomes [7, 9-11].

Agency theory explains what is sometimes referred to as the "principal-agent problem" and involves one person, the agent, who "acts for, on behalf of, or as the representative" of another person, the principal [12, page 134]. Two types of problems arise in principal-agent situations: first, when the goals or desires of the agent and principal differ and second, when the agent and principal have different levels of risk tolerance [13]. Contracts are central when analyzing the relationship between a principal and an agent [13]. This is because structuring incentives or increasing transparency are the primary means to align the interests of the principal and agent $[14,15]$.

Agency theory assumes that individuals are rational actors and will pursue their own self-interest $[13,14]$. This assumption frames much of the way in which agency theory is applied. The legacy of this paradigm with principal-agent problems can be seen across the world as the traditional and dominant means of construction project delivery.

Traditional project delivery is very transactional [16]. Users pay for design, designers pay for contractor services, contractors pay for subcontractors, and subcontractors pay individuals to perform jobs. In a PCI led IPD, leadership 
and the environment shift the value creation paradigm from goods/services transactions to goods/service interdependencies [16]. This generative process of cocreating an environment with shared vision, values, and vernacular changes the nature of the service and becomes the fundamental basis of value exchange. Employees are engaged in work they believe to be meaningful and are intrinsically motivated to complete tasks well and even seek innovative alternatives which might better accomplish some objective or task. This reduces the need for leadership to devise various methods of carrot-andstick incentives and frees employees to share responsibility and ideas. The end result in a PCI environment is an effectively executed project where shared vision, values, and vernacular are cocreated across the project. There are reduced waste, decreased delivery time, and reduced construction costs which can be reinvested in the project in better or more advanced equipment and designs, further reducing lifetime operating costs.

\section{Method}

We performed a case study of the design and construction phases of a major addition to a large Midwestern children's hospital. Our cased study followed a mixed method confirmatory model which included qualitative data, statistical analysis, and inference [17]. We conducted semistructured interviews with 17 IPD team members while we observed interactions on the site and in meetings. We also collected and analyzed financial and other artefactual data such as schedule deviations and training time. Interviewees ranged from the senior leadership team to on-site management. The general contractor has over 50 years of experience in the local and regional commercial design-build markets with plans for expansion nationally.

We wanted to examine the whole of the design-build process with an emphasis on interpersonal relationships that happen during PCI. Our interview questions and analysis of the artifacts encompassed the four general categories of artifacts involved in system analysis, signs, things, actions, and thoughts [18]. Interviews were coded in multiple rounds and final codes sorted into thematic bins with consideration for the interviewee's intention, words used, and context of the comment [19]. Liberal use of memos enabled the team to capture rich yet easily shareable data for later analysis [20]. Emerging themes from the interviews fed our system model (Figure 2). The use of thematic analysis to understand the qualitative portion of our case was an appropriate choice to help us explore how people understand the heuristics of the integrated project delivery process. All interview candidates were also asked to participate in behavioral event interviews which revolve around the interviewee describing their experiences in specific situations or during specific events [21].

Because we were working to understand PCI, the interpersonal relationships of this IPD project, it made sense to use a purposeful sampling methodology focused on the team responsible for delivering the project. Our sample consisted of 17 individuals from 4 stakeholder categories: the general contractor (CEO, two project managers, three superintendents), major subcontractors, customer (six executives), and consultants (two). These individuals represented four organizations. Interviews lasted between 35 and 75 minutes. Our semistructured interview protocol revolved around asking participants to, "Share an experience of why you believe this project was successful."

People use artifacts (signs, things, actions, and thoughts [18]) to create order from our complex world [22]. A unifying thought or idea helps organize artifacts [22, page 8]. We used artifacts to build on one another and create order from the complex design-build system [22]. During data collection, participants provided examples of artifacts used during their IPD experiences such as color-coded message boards and awarding "bambino" stickers for a particular jobwell-done in support of project goals (At the construction site, workers proudly pasted these stickers on their hard hats in a manner akin to the Ohio State University football tradition of awarding buckeye stickers for a particularly good play and pasting them on their helmets.).

Case studies of other IPD projects served as additional artifacts feeding our system analysis. With this baseline understanding of IPD and traditional design-build system components, multiple iterations of our system model were developed to help us conceptualize interactions as we compared our emerging visualization to the literature and our real-world experiences [23, 24]. Eventually our team developed a diagram that represents our understanding of the relationships between system components. This includes motivating factors such as trust, the contract framework, waste, and rework (Figure 2).

\section{Findings}

We found that PCI enabled lean construction practices and the IPD process during the production planning cycle. Activities such as daily huddles, sequence pull planning, color-up boards, load leveraging, and back-log tracking enabled communication and openly sharing ideas and progress toward goals. We also found an up cycle construction capital in excess of $\$ 500$ million benefits for the organization and the community, justifying the initial construction bond.

In order to quantify this we introduce the term "up cycle construction capital" which we define as the organizational and community benefits produced minus construction cost (Figure 1).

Up cycle benefits are evaluated in three general buckets, profit, people, and planet.

Examples of the 3Ps include reduced construction project costs, reduced life cycle costs such as energy savings, increased positive effect in the community, improved incremental revenues, safer conditions at the site and in the community, increased operating efficiencies, and individuals competence.

The general contractor in our case study claims to be more than a construction company. With a specialization in construction management they pride themselves in going beyond their expected role by providing innovation in the 


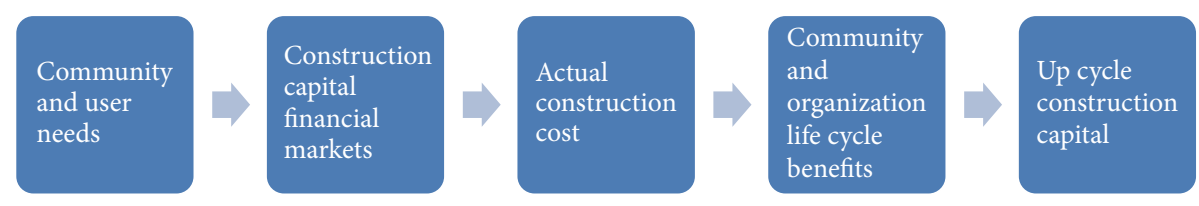

Figure 1: Up cycle construction capital.

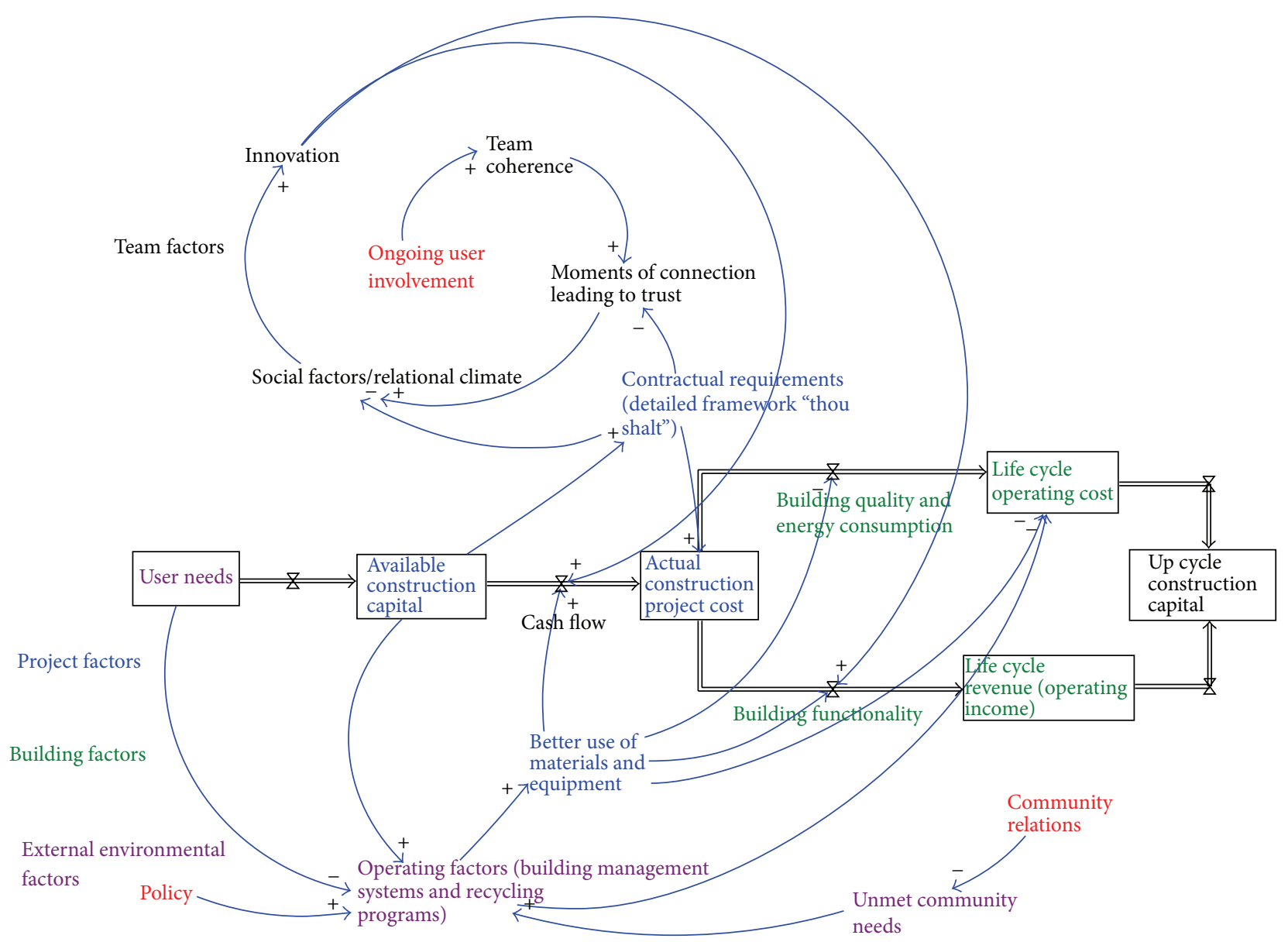

FIGURE 2

use of technology, being conscientious stewards of the environment, and supporting the community. At the outset of planning, the project was projected to cost $\$ 240 \mathrm{M}$ using traditional project delivery methods. Through the effective use of IPD, enabled by people centered innovation, the project was brought in at a final cost of $\$ 178.3 \mathrm{M}$, six months ahead of the projected schedule. Additionally, the quality of the product exceeded the original expectations of the stakeholders. During interviews, one of these stakeholders commented:

"I'm a believer in IPD and especially when you incorporate lean. It's got to be a better way... I'm sure you've read this statistic but there's something like 50\% waste in the construction industry, as they've defined waste, so here we are arguing about $1.75 \%$ and $2 \%$ fees and we've got $48 \%$ waste in a project. If we can get rid of some portion of the waste which benefits the client we probably can make a little more money or take the pressure of the profit side of the project and have everybody win. To me, that's where we've got to go. We can get paid what we are entitled to and the client gets the benefit of the project costing less overall."

A rigorous system of measurements is another critical element for effective IPD management. Clearly understood system-level measures help project personnel from all levels understand and focus on Up Cycle Construction Capital (profit, people, and planet). This maximizes the total system result of a construction project. According to another stakeholder member of the IPD team, “... it's not just first cost. Ultimately, you want to balance life-cycle operating expenses 
[with] ease of use [and] creature comforts.... so that we create success for the organization."

Progress signs and recognition such as the "bambino helmet stickers" are artifacts of an environment where the thoughts and actions of delivery team members are closely aligned and information openly shared. Key artifacts identified through our system model include contractual requirements (project factor), team coherence (team factor), community needs (external environmental factor), and life cycle cost/benefits (physical building factors). As noted earlier, contracts are central to the relationship between a principal and an agent and the manner in which incentives are structured in alignment with the motivations of the parties.

In our system analysis of the construction delivery process (see Figure 2), we identified artifacts in four areas, team factors in the form of human effect, cognition, and motivation; project factors such as contract mechanism and traditional project metrics such as cost, schedule, and waste; physical building factors which include quality, functionality, and life cycle operating factors; and finally, external environmental factors and considerations such as community needs, governmental requirements, and environmental policy.

We see the combination of these factors and the project results as an example of a successful people centered innovation led integrated project delivery. Our findings will point to the keys of this successful IPD implementation as being shared vision, values, and vernacular as well as emotionally intelligent leadership using lean building principles. A contract and process do not build buildings, people do.

\section{Discussion}

PCI led IPD success is based on the stakeholders having shared vision, values, vernacular, emotionally intelligent leadership, and a way to measure the up cycle benefits (3Ps, profit, people, planet) of decisions being made during the project. The CEO from the hospital set the vision for the project "We will design our new building through the eyes of a child." "We want the project team to reflect the values or our organization as they go about building our new hospital wing." The Akron Children's Hospital (ACH) guiding principles (Values) were put front and center for the entire building team. ACH's intention was to create a distinctive place in the community that is safe and comforting in the eyes of a child, parent, and staff. The culture surrounding the project delivery team was developed with these values as unifying themes. ACH places a value on having a respectful connection to the natural environment, being playful, and inspiring confidence and hope in those they touch; this is an example of elevating the consciousness of the project team and stakeholders, a critical element of PCI. The CEO of ACH would comment as to "how the feeling and interaction was just like being on the ACH main campus." The contractor commented, "We call it a zippered relationship. What's the board see as the big picture, what executives see as their mission and their role, what does middle management see and then right down into the facilities department, so if we can get those four levels all zippered up so that somebody from our side has a relationship with every single one of those levels, we get a better view of what the entire project's about."

Traditional project contracts are very transactional. A PCI led IPD project is typified by team members who identify and cocreate shared values and vision for the project and use a shared vernacular to communicate with one another. The resulting team coherence creates a relational climate of trust that is codified in the contractual requirements. In our case study of a PCI led IPD construction project, team coherence presented itself in many ways and created a sense of pride and identity amongst the participants. Here are some examples of what we found in our interviews of the building team. Even a year after their involvement in the project, many of the blue-collar construction workers still proudly point to their involvement with the project.

In the words one of our interviewees: "We are having celebratory lunches for 350 guys.... We have guys coming in after hours to play Santa Claus and hand out presents to the children.... The other weekend I was out in a bar and one of the workers came up to me, proudly wearing one of the T-Shirts we gave out as a safety award and commented how proud he was to be a part of the team that built the hospital wing."

The difference between this IPD and the traditional transaction-based, design bid build project is the intervention which continually involves the user of the space throughout the delivery process. Traditional projects may only include the user input at two points during the project delivery process: first during the initial requirements development activity at the beginning of a project, when a list of needs is translated into contract lines then not again until the acceptance phase which is after construction is completed or is nearing completion. Continual user involvement not only creates a sense of involvement and teamwork, but also provides a check during the act of building the space. This reduces waste and reworks saving both material and money. We saw an example of this when the delivery team used to-scale, physical mock-ups of entire floors of the building using cardboard. Not only were users (tenants) brought in to evaluate the functionality, but also the users' customers were brought in in some cases to provide input on the aesthetics. This is an example of people centered innovation.

As happens in the real world, there were instances where the structure deviated from the specification in the design. In a typical construction contract, the structure would have been torn down or overhauled at significant cost and time delay. In an environment of trust and team coherence, the client users understand that things happen in the real world. People were brought in who would eventually occupy the space to perform their work and give the space a test-run. Having had no prior knowledge of the design deviation, they reported the space worked better than they expected. The delivery team and user accepted the "as-built" structure and saved both time and cost thanks to a trusting environment and flexible contract mechanism. This single example accounted for 22,000 square foot reduction and 11 million in savings.

Including community needs expands the stakeholder group beyond the user tenants of the space to include the 
customers served by those user tenants. From the designbuild team's perspective this is the customer of the customer.

Community needs feed the operating systems incorporated into the structure and help it to find and address market gaps to better serve the community directly. This could present itself as energy efficiency or reduced waste from the operational building or during construction or even the use of prefabricated materials to reduce noise, construction time, and community disruption during the project. In our IPD case study, one aspect of meeting community needs presented itself via an intervention with community relations. The delivery team identified transportation as a problem for many of the low-income residents in the area. By including community leaders in the process, new bus routes were established to regularly serve the building and optimize the transportation costs for the community. These improvements not only have a positive impact on reducing life cycle operating costs and increasing operating revenue, but also can create positive relationships and a sense of identity or sense of community within the community and amongst the delivery team.

Emotional intelligence is a key leadership trait for effective people centered innovation (PCI) and integrated project delivery (IPD). At Akron Children's Hospital, the construction manager facilitated PCI by using emotionally intelligent leadership. The construction manager recognized project participants as team members on the project not as an end to their message but as a bridge for their message, a means to create and disseminate a shared vision and shared values.

"I think there's got to be a certain amount of empathy for other people that they're human that problems exist and hopefully they have the same respect for you that you're human and you're going to ... you can't be crucified every time you make a mistake and you can't go crucifying other people every time they make a mistake. Find a way to get it done, find a way to make it an enjoyable experience and that happens when you stay focused on what the mission needs to be; why are we doing this."

\begin{abstract}
"We do a stand down every Tuesday right after lunch where the entire project, all the guys, we get them all together and I let them pick the song of the week. It was Eye of the Tiger yesterday. We play a song, we talk about safety. Last week there was a guy up in Cleveland that died on a jobsite and we had a moment of silence. We had somebody who knew the guy to speak. It's an opportunity to bring everybody together."
\end{abstract}

Instead of acting as a boss dictating how something should be done, they engaged in a process of cocreation where the general contractor gave up control and jointly created a new and better way to achieve the objective. During the IPD building process team members would be asked to review "game tape." Game tape was actual video of team members performing a certain task. This was done with the full consent and knowledge of the team members doing the work. The team would then be asked to review the game tape "usually with pizza and were asked what they saw and was there any way to improve upon what they were doing - they were asked to be open, use their imagination, flexible, spontaneous and creative." Openness, flexibility, spontaneity, creativity, and being imaginative are all factors of cognitive play [25].

\section{Conclusion}

We believe that we have found the next level in the complex process of commercial construction that moves the needle in favor of long term survival of the planet. The integrated project delivery combined with people centered innovation enables cocreation by the core and extended project teams guided by a shared vision of both the short and long term future. This approach using people centered innovation could be the beginning of a new trajectory of the construction industry that revolves around up cycle design and life cycle planning implemented with integrated, lean construction methods, supported by cutting edge technology and visionary policies. Shared values established through concerns for the environment, health, and safety of worker and stakeholders, and social responsibility can become the new norms for the industry as a whole. A common vernacular built on inclusivity and participation can allow new ideas to flood the industry with future trends and innovative solutions intended to facilitate a new way of living and working in the built environment.

\section{Competing Interests}

The authors declare that there are no competing interests regarding the publication of this paper.

\section{References}

[1] Center for Sustainable Systems, "Commercial Buildings," Factsheet CSS05-05, University of Michigan, 2015, http:// css.snre.umich.edu/css_doc/CSS05-05.pdf.

[2] H. A. Simon, The Sciences of the Artificial, MIT Press, 3rd edition, 1996.

[3] J. Stempfle and P. Badke-Schaub, "Thinking in design teamsan analysis of team communication," Design Studies, vol. 23, no. 5, pp. 473-496, 2002.

[4] R. L. Edgeman and J. K. Eskildsen, "The C4 model of peoplecentered innovation: culture, consciousness, and customercentric co-creation," Journal of Innovation \& Business Best Practice, vol. 2012, Article ID 932564, 14 pages, 2012.

[5] M. J. Bongiorni and I. Cohort, Integrated Project Delivery, 2011.

[6] D. Baccarini, "The concept of project complexity-a review," International Journal of Project Management, vol. 14, no. 4, pp. 201-204, 1996.

[7] D. Goleman, Working With Emotional Intelligence, Random House Publishing Group, 2006, http://books.google.com/ books?id=9nuVVzkblNgC\&pgis=1.

[8] C. Laszlo and J. S. Brown, Flourishing Enterprise: The New Spirit of Business, Stanford Business Press, Stanford, Calif, USA, 2014. 
[9] D. Goleman, R. E. Boyatzis, and A. McKee, Primal Leadership: Learning to Lead With Emotional Intelligence-Kindle Edition, Harvard Business School Press, Boston, Mass, USA, 2002.

[10] D. Goleman, Emotional Intelligence: 10th Anniversary EditionKindle Edition, Bantam Dell, New York, NY, USA, 2005.

[11] V. U. Druskat and S. B. Wolff, "Building the emotional intelligence of groups," Harvard Business Review, vol. 79, no. 3, pp. 80-164, 2001.

[12] S. A. Ross, "The economic theory of agency: the principal's problem," The American Economic Review, vol. 63, no. 2, pp. 134-139, 1973.

[13] K. M. Eisenhardt, "Agency theory: an assessment and review," Academy of Management Review, vol. 14, no. 1, pp. 57-74, 1989.

[14] P. D. Harrison and A. Harrell, "Impact of 'adverse selection' on managers' project evaluation decisions," Academy of Management Journal, vol. 36, no. 3, pp. 635-643, 1993.

[15] A. Keegan and J. R. Turner, "The management of innovation in project-based firms," Long Range Planning, vol. 35, no. 4, pp. 367-388, 2002.

[16] S. L. Vargo and R. F. Lusch, "Evolving to a new dominant logic for marketing," Journal of Marketing, vol. 68, pp. 1-17, 2004.

[17] C. Teddlie and A. Tashakkori, Foundations of Mixed Methods Research Integrating Quantitative and Qualitative Approaches in the Social and Behavioral Sciences, Sage Publications, Thousand Oaks, Calif, USA, 2006.

[18] L. Kimbell, "Rethinking design thinking: part 1," Design and Culture, vol. 3, no. 3, pp. 285-306, 2011.

[19] J. Saldana, The Coding Manual for Qualitative Researchers, Sage, 2nd edition, 2013.

[20] K. Charmaz, Constructing Grounded Theory: A Practical Guide Through Qualitative Analysis, Sage, 2006.

[21] R. E. Boyatzis, "Competencies as a behavioral approach to emotional intelligence," Journal of Management Development, vol. 28, no. 9, pp. 749-770, 2009.

[22] V. Margolin and R. Buchanan, The Idea of Design, The MIT Press, Cambridge, Mass, USA, 1995.

[23] F. Kensing and J. Blomberg, Participatory Design: Issues and Concerns. Computer Supported Cooperative Work, Kluwer Academic, 1998.

[24] T. Brown, Design Thinking, Harvard Business Review, Boston, Mass, USA, 2008.

[25] M. A. Glynn and J. Webster, "Refining the nomological net of the adult playfulness scale: personality, motivational, and attitudinal correlates for highly intelligent adults," Psychological Reports, vol. 72, pp. 1023-1026, 1993. 


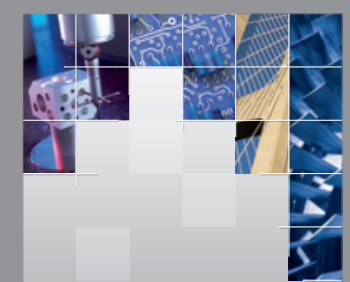

\section{Enfincering}
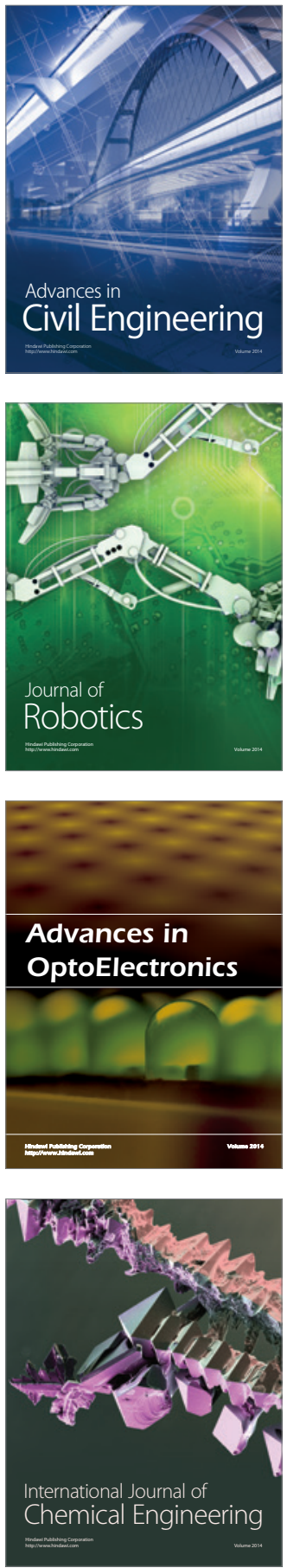

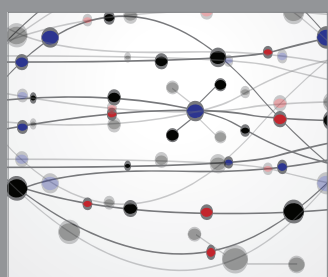

The Scientific World Journal

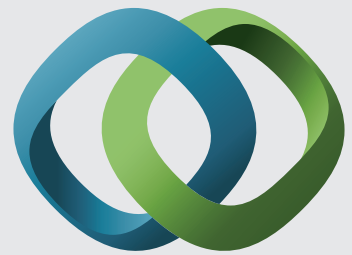

\section{Hindawi}

Submit your manuscripts at

http://www.hindawi.com
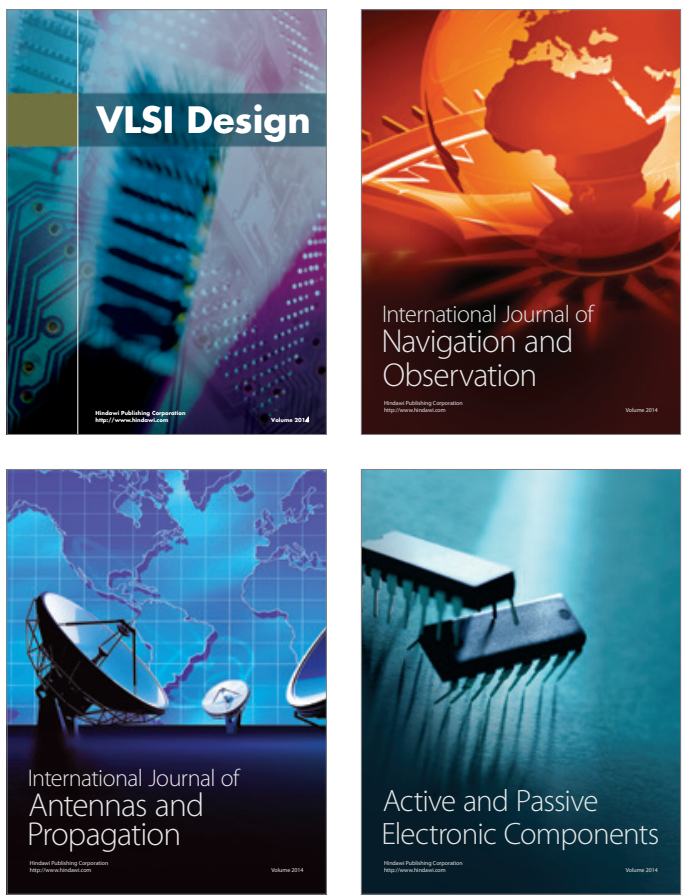
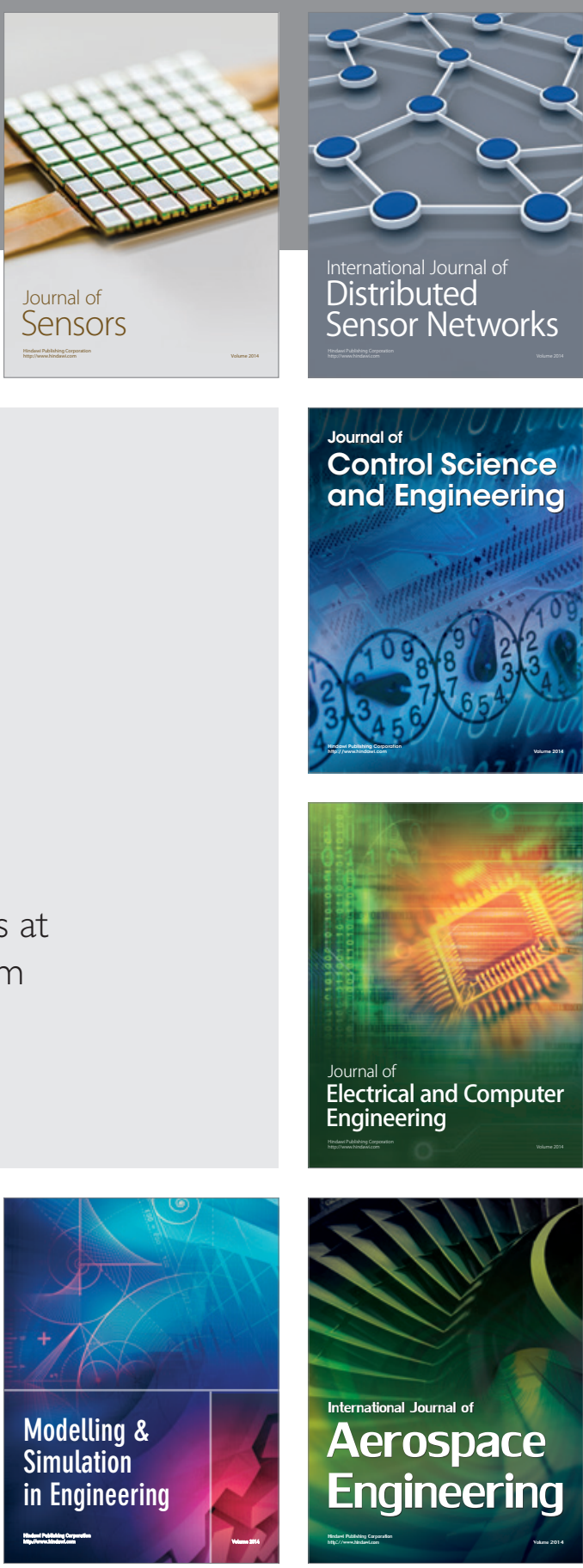

International Journal of

Distributed

Sensor Networks

Journal of

Control Science

and Engineering
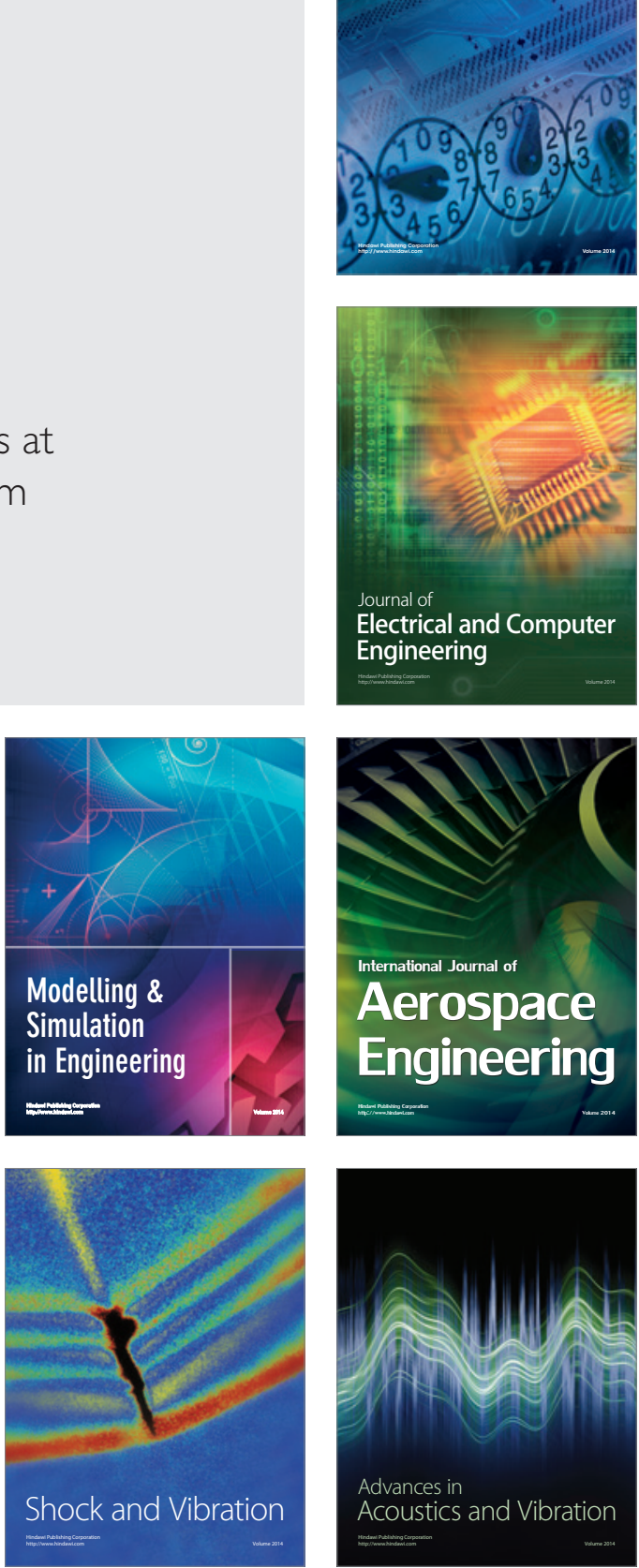